Journal of Acute Disease

journal homepage: www.jadweb.org

Original article https://doi.org/10.12980/jad.6.2017JADWEB-2016-0061

(C2017 by the Journal of Acute Disease. All rights reserved.

\title{
Curative effect of minimally invasive puncture and drainage assisted with alteplase on treatment of acute intracerebral hemorrhage
}

Jun-Lin $\mathrm{Hu}^{*}$, Cheng Zhang, Jian-Ming Li

Department of Neurosurgery, Zigong Third People's Hospital, Zigong 643020, Sichuan, China

\section{ARTICLE INFO}

Article history:

Received 30 Aug 2016

Accepted 3 Oct 2016

Available online 8 Dec 2016

Keywords:

Acute intracerebral hemorrhage

Alteplase

Inflammatory reaction

Oxidative stress response

\begin{abstract}
Objective: To investigate the different effects on evacuation of hematoma, the severity of nerve injury, inflammatory reaction and oxidative stress response in the treatment of acute intracerebral hemorrhage by using minimally invasive puncture and drainage assisted with alteplase or urokinase.

Methods: A total of 114 patients with acute intracerebral hemorrhage treated with minimally invasive puncture and drainage in our hospital from May 2012 to October 2015 were retrospectively analyzed and divided into alteplase group and urokinase group, which received adjuvant therapy with alteplase and urokinase, respectively. Before and after treatment, CT was used for scanning, and the volume of hematoma and edema and the distance of midline shift were examined. After treatment, serum was collected for detecting the contents of molecular markers of nerve injury, inflammatory reaction and oxidative stress response.

Results: On the 3rd day after treatment, the volume of hematoma and edema and the distance of midline shift in minimally invasive group were significantly lower than those of craniotomy group, and incidence of intracranial infection was lower than that of craniotomy group. There was no significant difference of rebleeding incidence compared to craniotomy group. The serum contents of osteopontin, S100 $\beta$, glial fibrillary acidic protein, neuron-specific enolase, myelin basic protein, neuropeptide $\mathrm{Y}$, ischemia modified albumin, tumor necrosis factor alpha, interleukin-1 $\beta$, interleukin-6, interleukin-8, soluble intercellular adhesion molecule-1, highmobility group protein 1 , malonaldehyde, advanced oxidation protein products and 8-hydroxy2'-deoxyguanosine urine of patients from alteplase group were significantly lower than those of urokinase group. The content of total antioxidant capacity was obviously higher than that of urokinase group.

Conclusions: As for the effect on evacuation of hematoma and also the ameliorative effect on nerve injury, inflammatory reaction and oxidative stress response in treatment of acute intracerebral hemorrhage, minimally invasive puncture and drainage assisted with alteplase was superior to adjuvant therapy with urokinase.
\end{abstract}

\section{Introduction}

Intracerebral hemorrhage is a common type of brain stroke in clinic which accounts for about $10 \%-15 \%$ of all brain strokes. Acute intracerebral hemorrhage has a rapid development in disease condition, and its disability and fatality rate are very high[1,2]. When intracerebral hemorrhage occurs, the occupied effect caused by hematoma will lead to a raise of intracranial pressure, a compression to brain tissue and primary damage of brain tissue, and in severe

*Corresponding author: Jun-Lin Hu, Department of Neurosurgery, Zigong Third People's Hospital, Zigong 643020, Sichuan, China.

Tel: +86 15700665598

E-mail: hujunlin10@163.com

The study protocol was performed according to the Helsinki declaration and approved by the ethic committee of Zigong Third People's Hospital. Informed written consent was obtained from patients' family members.

Foundation Project: Supported by Scientific Research Project of Sichuan Health Department, Sichuan, China (Grand No. 130149).

The journal implements double-blind peer review practiced by specially invited international editorial board members. cases cerebral hernia may occur. Except the effect of primary damage caused by intracerebral hemorrhage, the inflammatory reaction and oxidative stress response produced by decomposition of hematoma in local metabolism will result in the apoptosis of neuron and neurogliocyte and then the secondary damage to brain tissue occurs. In the developing process of disease condition in patients with acute intracerebral hemorrhage, the interaction and mutual promotion by primary damage and secondary damage will both cause the raise of intracranial pressure, brain edema and neural function damage[3,4]. Therefore, once the patients are diagnosed acute intracerebral hemorrhage and present with large amount of bleeding and obvious intracranial occupied effect, they need the emergency surgical treatment to remove the intracranial hematoma[5].

At present, emergency minimally invasive puncture and drainage is the most common way to treat acute intracerebral hemorrhage 
in clinic. As compared to the conventional craniotomy evacuation of hematoma, minimally invasive surgery causes lesser secondary damage to brain tissue and has a higher efficiency to remove the intracranial hematoma, and it also has a significant effect for reducing the intracranial pressure and brain edema[6,7]. Recent clinical researches have noticed that the minimally invasive puncture and drainage simultaneously along with the clot dissolution can achieve a significant effect to improve the evacuation of hematoma. Urokinase is the most widely used medicine for clot dissolution at present, which has a certain fibrinolytic system effect and can effectively dissolve the intracranial clot caused by intracerebral hemorrhage. However, due to its relatively poor specificity on fibrinolytic effect, it will easily cause systemic hyperfibrinolysis and increase the occurrence risk of rebleeding[8,9]. Alteplase is a new-type drug for dissolving hematoma compounded by genetic engineering technology which has a high selectivity of fibrous protein and a good effect on clot dissolution[10]. In the following study, we analyzed the effects on evacuation of hematoma, the severity of nerve injury and the difference between inflammatory reaction and oxidative stress response in treatment of acute intracerebral hemorrhage by minimally invasive puncture and drainage assisted with alteplase and urokinase.

\section{Materials and methods}

\subsection{Cases recruited}

Case data of 114 patients with acute intracerebral hemorrhage treated with minimally invasive puncture and drainage in our hospital from May 2012 to October 2015 were colleted and retrospectively analyzed. The inclusion criteria were as follow: (1) Diagnosis standard of acute intracerebral hemorrhage was met, and the hematoma was found at the basal ganglia, thalamus and lobe with a volume of $20-60 \mathrm{~mL}$ by CT after admitting to hospital (2) Patients presented with disturbance of consciousness, limb movement disorder and feeling dysfunction; (3) Glasgow coma scale was more than 5 and patients were not complicated with cerebral hernia; (4) Time from onset to receiving treatment was less than $24 \mathrm{~h}$; (5) Patients accepted the treatment of emergency minimally invasive puncture and drainage; (6) Case data were complete and serum specimens were completely collected.

The study protocol was performed according to the Helsinki declaration and approved by the ethic committee of Zigong Third People's Hospital. Informed written consent was obtained from patients' family members.

\subsection{Grouping and therapeutic methods}

Case data of patients with intracerebral hemorrhage were retrospectively analyzed and divided into alteplase group and urokinase group according to the different drugs used for hematoma dissolving in minimally invasive puncture and drainage. There were a total of 48 cases in alteplase group, and the therapeutic methods were as follow. The location and direction of puncture were confirmed according to the scan results of $\mathrm{CT}$, which should avoid the main functional areas of brain tissue, important nerves and vessels. YL-1 type of hematoma smashing needle was applied. The suction volume of hematoma after successfully puncturing should be less than $30 \%$ of total volume. Then normal saline was used to repeatedly wash till the liquid color elicited turned light, and the drainage tube was clamped. The puncture needle was confirmed to locate in the hematoma cavity according to $\mathrm{CT}$ reexamination after surgery. Then 1-2 mg of alteplase and $5 \mathrm{~mL}$ of normal saline were injected into the hematom 2-3 times a day for continuous 3 days. And the drainage tube was clamped for 1-2 $\mathrm{h}$ before opened each time. There were a total of 66 cases in urokinase group, and the therapeutic methods were as follow. The operation of minimally invasive puncture and drainage was the same as that of the alteplase group. When the puncture needle was confirmed to be located in the hematoma cavity, $30000 \mathrm{IU}$ of urokinase and $5 \mathrm{~mL}$ of normal saline were injected into the hematom 2-3 times a day for continuous 3 days. And the drainage tube was clamped for $1-2 \mathrm{~h}$ before opened each time.

\subsection{Evaluation methods for the evacuation of hematoma}

Before the surgery and on the 3rd day after surgery, CT was used for scanning, and software Kingstar winning Pacs this view version 3.02 was applied in the measurement of the length, width and thickness of the largest layer of hematoma after image information was obtained. The volume of hematoma was calculated by the following formula:

The volume of hematoma $=$ Length $\times$ Width $\times$ Thickness $\times \pi / 6$.

The complex volume of brain edema and hematoma was measured in the same way, and the volume of brain edema was calculated by the following formula:

The volume of brain edema = Complex volume of brain edema and hematoma - The volume of hematoma.

The distance between brain midline and original midline was measured at the most obvious part of midline shift.

\subsection{Collection and detection methods of serum indexes}

On the 3rd day after treatment, five milliliter of peripheral venous blood was collected and centrifuged to obtain the serum. Then ELISA was used to detect the contents of osteopontin (OPN), S100ß, glial fibrillary acidic protein (GFAP), neuron-specific enolase (NSE), myelin basic protein (MBP), neuropeptide Y (NPY) and ischemia modified albumin (IMA). Radioimmunoprecipitation was used to detect the contents of total antioxidant capacity (T-AOC), malonaldehyde (MDA), advanced oxidation protein products (AOPP) and 8-hydroxy-2'-deoxyguanosine urine (8-OHdG).

\subsection{Statistical analysis}

Software SPSS version 19.0 was used to input and analyze the data. Measurement data were expressed as mean \pm SD and analyzed by $t$-test. Enumeration data were expressed by frequency and analyzed 
by $C h i$-square. Difference was considered statistically significant when $P<0.05$.

\section{Results}

\subsection{The evacuation of hematoma of two groups}

There was no significant difference in the volumes of hematoma and edema, and the midline shift distance between the two groups before the treatment. On the 3rd day after the treatment, the volumes of hematoma and edema, the midline shift distance from minimally invasive group were significantly lower than those of craniotomy group, and incidence rate of rebleeding was lower than that of craniotomy group. There was no significant difference in the incidence rate of intracranial infection compared to craniotomy group. Differences in the volumes of hematoma and edema, the midline shift distance of the two groups on the 3rd day after treatment were considered statistically significant $(P<0.05)$. Difference in the incidence rate of intracranial infection was not statistically significant $(P>0.05)$ (Table 1$)$.

\subsection{Molecular markers of nerve injury in the serum}

On the 3rd day after treatment, the contents of serum OPN [(5.52 \pm $0.81) v s .(7.56 \pm 0.93) \mathrm{ng} / \mathrm{mL}], \mathrm{S} 100 \beta[(0.94 \pm 0.11) v s .(1.68 \pm 0.20)$ $\mathrm{ng} / \mathrm{mL}]$, GFAP $[(1.78 \pm 0.23) v s .(3.47 \pm 0.49) \mathrm{pg} / \mathrm{mL}]$, NSE [(27.39 $\pm 3.96) v s .(47.15 \pm 6.79) \mathrm{ng} / \mathrm{mL}]$, MBP $[(3.49 \pm 0.48) v s$. $(6.45 \pm$ $0.79) \mathrm{ng} / \mathrm{mL}], \mathrm{NPY}[(89.65 \pm 9.34) v s .(132.32 \pm 17.69) \mathrm{ng} / \mathrm{mL}]$, IMA $[(49.52 \pm 6.74) v s .(64.59 \pm 9.42) \mathrm{IU} / \mathrm{mL}]$ from alteplase group were significantly lower than those of urokinase group. Differences in the serum contents of OPN, S100 $\beta$, GFAP, NSE, MBP, NPY, IMA between the two groups on the 3rd day after treatment were statistically significant $(P<0.05)$.

\subsection{Molecular markers of inflammatory reaction and oxidative stress response in the serum}

On the 3rd day after treatment, the serum contents of tumor necrosis factor alpha $(\mathrm{TNF}-\alpha)[(85.62 \pm 9.52) v s .(129.42 \pm 16.54)$ $\mathrm{pg} / \mathrm{mL}]$, interleukin-1 $\beta(\mathrm{IL}-1 \beta)[(6.53 \pm 0.83) v s .(9.41 \pm 1.03) \mathrm{pg} /$ $\mathrm{mL}], \mathrm{IL}-6[(47.62 \pm 6.41) v s .(65.49 \pm 7.85) \mathrm{pg} / \mathrm{mL}], \mathrm{IL}-8$ [(32.21 $\pm 4.49) v s .(56.52 \pm 6.75) \mathrm{pg} / \mathrm{mL}$, soluble intercellular adhesion molecule-1 (sICAM-1) [(103.59 \pm 15.49$) v s .(178.87 \pm 22.15) \mathrm{ng} /$ $\mathrm{mL}]$, high-mobility group box 1 protein (HMGB-1) [(143.54 \pm 19.34$)$ vs. $(259.31 \pm 33.49) \mathrm{ng} / \mathrm{mL}]$, MDA $[(5.42 \pm 0.89)$ vs. $(8.41 \pm 1.08)$ $\mu \mathrm{mol} / \mathrm{L}]$, AOPP $[(47.36 \pm 6.53) v s .(95.58 \pm 10.37) \mu \mathrm{mol} / \mathrm{L}]$ and 8-OHdG $[(3.69 \pm 0.49) v s .(6.28 \pm 0.77) \mathrm{ng} / \mathrm{mL}]$ from alteplase group were significantly lower than those of urokinase group, and content of T-AOC $[(22.49 \pm 3.36) v s .(14.42 \pm 1.98) \mathrm{IU} / \mathrm{mL}]$ was higher than that of urokinase group. Differences in the serum contents of TNF- $\alpha$, IL-1 $\beta$, IL-6, IL-8, sICAM-1, HMGB-1, T-AOC, MDA, AOPP and 8-OHdG from the two groups on the 3rd day after treatment were statistically significant $(P<0.05)$.

\section{Discussion}

Acute intracerebral hemorrhage has a dangerous condition which can damage the neural function and maintains a very high fatality and disability rate. Mechanism of neural function damage caused by intracerebral hemorrhage includes primary damage and secondary damage. Primary damage refers to the compression of brain tissue caused by the occupied effect of hematoma, which leads to a raise of intracranial pressure, cerebral hernia and further the neural function damage. Secondary damage refers to the inflammatory reaction and oxidative stress response caused by production of hematoma catabolism, which will result in the apoptosis of neuron and neuroglia, and further the neural function damage. Minimally invasive puncture and drainage assisted with hematoma dissolving drugs is a common way for emergency treatment of acute intracerebral hemorrhage in clinic. Minimally invasive surgery can evacuate the hematoma with very little injury. The hematoma and the intracranial pressure can be efficently removed and reduced when the surgery is assisted with hematoma dissolving drugs[1113]. Urokinase is a hematoma dissolving drug the most widely used with a certain fibrinolytic system effect. However, its biggest defect is the poor specificity and low affinity to the local fibrin. It will cause systemic hyperfibrinolysis and further increase the occurrence risk of rebleeding when dissolving hematoma at the same time[14]. Alteplase is an emerging new-type hematoma dissolving drug in recent years, also a plasminogen activator compounded by using genetic engineering technology, which has a high selectivity of fibrous protein. It will not cause hyperfibrinolysis when dissolving hematoma[15-17]. We can see by analyzing the evacuation of hematoma with two assistant hematoma dissolving drugs in the treatment of acute intracerebral hemorrhage, that the volumes of hematoma and edema, the midline shift distance and incidence rate of rebleeding from alteplase group were significantly lower than those of urokinase group, which indicated that as for the effect on evacuation of hematoma, adjuvant therapy with alteplase was superior to that with urokinase, and the recurrence risk of

Table 1

The evacuation of hematoma of the two groups.

\begin{tabular}{|c|c|c|c|c|c|c|c|c|}
\hline \multirow[t]{2}{*}{ Group } & \multicolumn{3}{|c|}{ Before treatment } & \multicolumn{5}{|c|}{ After treatment } \\
\hline & $\begin{array}{c}\text { Volume of } \\
\text { hematoma }(\mathrm{mL})\end{array}$ & $\begin{array}{c}\text { Volume of } \\
\text { edema }(\mathrm{mL})\end{array}$ & $\begin{array}{l}\text { Midline shift } \\
\text { distance }(\mathrm{mm})\end{array}$ & $\begin{array}{l}\text { Volume of } \\
\text { hematoma } \\
(\mathrm{mL})\end{array}$ & $\begin{array}{c}\text { Volume of } \\
\text { edema }(\mathrm{mL})\end{array}$ & $\begin{array}{l}\text { Midline shift } \\
\text { distance }(\mathrm{mm})\end{array}$ & $\begin{array}{l}\text { Rebleeding } \\
\text { rate }[(n) \%]\end{array}$ & $\begin{array}{c}\text { Intracranial } \\
\text { infection rate } \\
{[(n) \%]}\end{array}$ \\
\hline Alteplase group $(n=48)$ & $33.42 \pm 4.49$ & $51.32 \pm 6.76$ & $4.42 \pm 0.59$ & $7.69 \pm 0.93$ & $16.65 \pm 1.93$ & $1.54 \pm 0.18$ & $2(4.17)$ & $3(6.25)$ \\
\hline Urokinase group $(n=66)$ & $33.19 \pm 3.94$ & $50.94 \pm 7.14$ & $4.56 \pm 0.65$ & $11.34 \pm 1.45$ & $24.89 \pm 3.42$ & $2.29 \pm 0.35$ & $10(15.15)$ & $5(7.58)$ \\
\hline$P$ & $>0.05$ & $>0.05$ & $>0.05$ & $<0.05$ & $<0.05$ & $<0.05$ & $<0.05$ & $>0.05$ \\
\hline
\end{tabular}

Values were expressed as mean \pm SD. 
intracerebral hemorrhage was also lower than that with urokinase assisted therapy.

When the neuron cells and neurogliocyte of brain tissue were affected by the combined effects of primary damage and secondary damage, the cells will result in rupture, and the blood brain barrier will be damaged as well. Various molecules of neuron and spongiocyte will get into the blood circulation through the damaged blood brain barrier, and the severity of nerve injury can be demonstrated by detecting the contents of related molecular markers in serum. OPN is mainly expressed in the blood brain barrier, which has a maintenance effect on both the close connection of the epithelium and endothelial cells, and the integrity of blood brain barrier. The damage of blood brain barrier will lead to the release of OPN into blood circulation[18]. S100 $\beta$ and NSE are mainly expressed in the neuron cells, while the former one participates in the regulation of intracellular calcium homeostasis and the dynamic change of cytoskeletal components, and the latter one gets involve with the regulation of energy metabolism in the cell[19-21]. GFAP and MBP are mainly expressed in the neurogliocyte which participates in the formation of cytoskeleton and the regulation and control of cell membrane stability[22,23]. NPY mainly distributes in the neuron and its neurite, and it is involved with the regulation and control of the sympathetic nerve system activity. The damage of neuron and spongiocyte will lead to a release of the above molecules into blood circulation[24,25]. IMA is a product of the combination of albumin under hypoxic-ischemic condition with divalent metal ion. Local occupied effect of intracerebral hemorrhage will cause a hypoxicischemic condition and further increase the production of IMA. To confirm that whether the evacuation of hematoma following the adjuvant therapy with alteplase can reduce the neural function damage or not, we detected the contents of above molecular markers in serum, and the results showed that the serum contents of OPN, S100ß, GFAP, NSE, MBP, NPY and IMA from alteplase group were significantly lower than those of urokinase group, which indicated that the adjuvant therapy with alteplase for patients with acute intracerebral hemorrhage can reduce the neural function damage.

Constant damage of neural function from patients with acute intracerebral hemorrhage closely relates to the secondary damage caused by hematoma. The hematoma and proximal brain edema stay in a high level of inflammatory reaction and oxidative stress response. Neural function can be damaged through inflammatory and oxidative damage mechanisms both during the constant existence of hematoma and some time after hematoma is removed. Inflammatory factors TNF- $\alpha$, IL-1 $\beta$, IL-6, IL-8, sICAM-1 and HMGB-1 are important mediums mediating the inflammatory damage of neural function[26]. TNF- $\alpha$ is produced by mononuclear macrophage, which can not only improve the activation of various inflammatory cells, but also directly damage endothelial cells and aggravate brain edema at the same time. IL-1 $\beta$ is secreted by various inflammatory cells such as neutrophil granulocyte and mononuclear macrophage, which can directly damage the neuron and spongiocyte[27]. IL-6 and IL-8 play a role as endogenous chemotactic factors which can improve the intralesional aggregation of inflammatory cells and activate the inflammatory reaction[28]. sICAM- 1 is a soluble form of intercellular adhesion molecule- 1 which can improve the adherence of inflammatory cells in local nidus and blood vessel endothelium. HMGB-1 is an important proinflammatory cytokine which can stimulate the secretion of various inflammatory mediators[29]. sICAM and HMGB-1 collectively mediate the cascade amplification of inflammatory reaction. We can know by analyzing the contents of the above inflammatory factors, that the contents of TNF- $\alpha$, IL$1 \beta$, IL-6, IL-8, sICAM-1 and HMGB-1 in serum from alteplase group were significantly lower than those of urokinase group. Oxidative stress damage is mainly mediated by oxygen free radicals. When the lipid, protein and nucleic acid in cells have oxidative reaction, the cell structure and function will be damaged, and the relative productions are MDA, AOPP and 8-OHdG. At the same time, oxygen free radicals will massively consume the antioxidant substance in local tissue and further weaken the oxidation resistance[30-32]. We can see by analyzing the molecular markers of oxidative stress, that the serum contents of MDA, AOPP and 8-OHdG from alteplase group were significantly lower than those of urokinase group. T-AOC was significantly higher than that of urokinase group. The above analysis of molecular markers of inflammatory reaction and oxidative stress response has showed that adjuvant therapy with alteplase for patients with acute intracerebral hemorrhage can reduce the secondary neural function damage mediated by inflammatory reaction and oxidative stress response.

In conclusion, as for the effect on evacuation of hematoma and also the ameliorative effect on nerve injury, inflammatory reaction and oxidative stress response in treatment of acute intracerebral hemorrhage, minimally invasive puncture and drainage assisted with alteplase was superior to adjuvant therapy with urokinase.

\section{Conflict of interest statement}

The authors report no conflict of interest.

\section{Acknowledgments}

This study is supported by Scientific Research Project of Sichuan Health Department, Sichuan, China (Grand No. 130149).

\section{References}

[1] Zhang XH, Wang QM, Chen H, Chen YH, Han W, Wang FR, et al. Clinical characteristics and risk factors of intracranial hemorrhage in patients following allogeneic hematopoietic stem cell transplantation. Ann Hematol 2016; 95(10): 1637-43.

[2] Owattanapanich W, Auewarakul CU. Intracranial hemorrhage in patients with hematologic disorders: prevalence and predictive factors. J Med Assoc Thai 2016; 99(1): 15-24.

[3] Wu L, Chen G. Signaling pathway in cerebral vasospasm after subarachnoid hemorrhage: news update. Acta Neurochir Suppl 2016; 121: $161-5$.

[4] Ji C, Chen G. Signaling pathway in early brain injury after subarachnoid hemorrhage: news update. Acta Neurochir Suppl 2016; 121: 123-6. 
[5] Hauguel M, Boelle P, Pichereau C, Bourcier S, Bigé N, Baudel $\mathrm{JL}$, et al. Severe extra-cerebral anticoagulant-related bleeding in intensive care unit: a retrospective study from 2000 to 2013. Medicine (Baltimore) 2015; 94(47): e2161.

[6] Yan YF, Ru DW, Du JR, Shen X, Wang ES, Yao HB. The clinical efficacy of neuronavigation-assisted minimally invasive operation on hypertensive basal ganglia hemorrhage. Eur Rev Med Pharmacol Sci 2015; 19(14): 2614-20.

[7] Yang Z, Hong B, Jia Z, Chen J, Ge J, Han J, et al. Treatment of supratentorial spontaneous intracerebral hemorrhage using imageguided minimally invasive surgery: initial experiences of a flat detector CT-based puncture planning and navigation system in the angiographic suite. AJNR Am J Neuroradiol 2014; 35(11): 2170-5.

[8] Gaberel T, Montagne A, Lesept F, Gauberti M, Lemarchand E, Orset $\mathrm{C}$, et al. Urokinase versus alteplase for intraventricular hemorrhage fibrinolysis. Neuropharmacology 2014; 85: 158-65.

[9] Garge SS, Shah VD, Surya N, Khadilkar SS, Modi PD, Ghatge SB. Role of local thrombolysis in cerebral hemorrhagic venous infarct. Neurol India 2014; 62(5): 521-4.

[10] Dong MX, Hu QC, Shen P, Pan JX, Wei YD, Liu YY, et al. Recombinant tissue plasminogen activator induces neurological side effects independent on thrombolysis in mechanical animal models of focal cerebral infarction: a systematic review and meta-analysis. PLoS One 2016; 11(7): e0158848.

[11] Fiorella D, Arthur A, Schafer S. Minimally invasive cone beam CTguided evacuation of parenchymal and ventricular hemorrhage using the Apollo system: proof of concept in a cadaver model. J Neurointerv Surg 2015; 7(8): 569-73.

[12] Xu F, Tang Z, Luo X, Kang H, Zhu W, Wang G, et al. Pneumocephalus following the minimally invasive hematoma aspiration and thrombolysis for ICH. Br J Neurosurg 2014; 28(6): 776-81.

[13] Qin Y, Gu JW, Li GL, Xu XH, Yu K, Gao FB. Cerebral vasospasm and corticospinal tract injury induced by a modified rat model of subarachnoid hemorrhage. J Neurol Sci 2015; 358(1-2): 193-200.

[14] Asakuno K, Ishida A. Intraarterial vasodilator therapy immediately rescued pure cortical deafness due to bilateral cerebral vasospasm. Surg Neurol Int 2014; 5: 61.

[15] Hong JH, Sohn SI, Kang J, Jang MU, Kim BJ, Han MK, et al. Endovascular treatment in patients with persistent internal carotid artery occlusion after intravenous tissue plasminogen activator: a clinical effectiveness study. Cerebrovasc Dis 2016; 42(5-6): 387-94.

[16] Chen Y, Li CH, Wang YX, Zhang CH, Dong Z, Zhang FF, et al. Safety and effectiveness of intravenous thrombolysis with recombinant tissue plasminogen activator in eighty years and older acute ischemic stroke patients. Eur Rev Med Pharmacol Sci 2015; 19(10): 1852-8.

[17] Barreto AD, Fanale CV, Alexandrov AV, Gaffney KC, Vahidy FS, Nguyen $\mathrm{CB}$, et al. Prospective, open-label safety study of intravenous recombinant tissue plasminogen activator in wake-up stroke. Ann Neurol 2016; 80(2): 211-8.

[18] Okyay K, Tavil Y, Sahinarslan A, Tacoy G, Turfan M, Sen N, et al. Plasma osteopontin levels in prediction of prognosis in acute myocardial infarction. Acta Cardiol 2011; 66(2): 197-202.

[19] Azurmendi L, Degos V, Tiberti N, Kapandji N, Sanchez-Peña P,
Sarrafzadeh A, et al. Neopterin plasma concentrations in patients with aneurysmal subarachnoid hemorrhage: correlation with infection and long-term outcome. J Neurosurg 2016; 124: 1287-99.

[20] Nguyen DN, Huyghens L, Wellens F, Schiettecatte J, Smitz J, Vincent JL. Serum S100B protein could help to detect cerebral complications associated with extracorporeal membrane oxygenation (ECMO). Neurocrit Care 2014; 20(3): 367-74.

[21] Moritz S, Warnat J, Bele S, Graf BM, Woertgen C. The prognostic value of NSE and S100B from serum and cerebrospinal fluid in patients with spontaneous subarachnoid hemorrhage. J Neurosurg Anesthesiol 2010; 22(1): 21-31.

[22] Xia XH, Zhou CL, He XN, Zhang GW. [The reference value of $\mathrm{S}-100 \mathrm{~B}$ and GFAP levels in serum for the diagnosis and evaluation of disease condition of traumatic brain injury]. $J$ Third Mil Med Univ 2014; 36(3): 283-6. Chinese.

[23] Su E, Bell MJ, Kochanek PM, Wisniewski SR, Bayir H, Clark RS, et al. Increased CSF concentrations of myelin basic protein after TBI in infants and children: absence of significant effect of therapeutic hypothermia. Neurocrit Care 2012; 17(3): 401-7.

[24] Rasmussen R, Stavngaard T, Jessing IR, Skjøth-Rasmussen J, Olsen NV, Ostrowski SR, et al. High plasma levels of neuropeptide y correlate with good clinical outcome but are not correlated to cerebral blood flow or vasospasm after subarachnoid hemorrhage. J Neurosurg Anesthesiol 2016; 28(1): 65-70.

[25] Açıkgöz Ş, Can M, Güven B, Edebali N, Barut F, Büyükuysal Ç, et al. Cystain $\mathrm{C}$ and neuropeptid $\mathrm{Y}$ levels in brain tissues after experimental subarachnoid hemorrhage. Acta Biochim Pol 2014; 61(4): 825-8.

[26] Wang XM, Zhang YG, Li AL, Long ZH, Wang D, Li XX, et al. Expressions of serum inflammatory cytokines and their relationship with cerebral edema in patients with acute basal ganglia hemorrhage. Eur Rev Med Pharmacol Sci 2016; 20(13): 2868-71.

[27] Wei P, You C, Jin H, Chen H, Lin B. Correlation between serum IL1 beta levels and cerebral edema extent in a hypertensive intracerebral hemorrhage rat model. Neurol Res 2014; 36(2): 170-5.

[28] Kao HW, Lee KW, Kuo CL, Huang CS, Tseng WM, Liu CS, et al. Interleukin-6 as a prognostic biomarker in ruptured intracranial aneurysms. PLoS One 2015; 10(7): e0132115.

[29] Sun Q, Wu W, Hu YC, Li H, Zhang D, Li S, et al. Early release of high-mobility group box 1 (HMGB1) from neurons in experimental subarachnoid hemorrhage in vivo and in vitro. J Neuroinflammation 2014; 11: 106.

[30] Dai QD, Si JC, Xu ZH, Yang CH, Zhang JP. The change of inflammatory cytokines and products of oxidative stress in the patients with acute cerebral hemorrhage and its clinical significance. Chin $J$ Clin (Electronic Edition) 2014; 8(3): 398-402. Chinese.

[31] Caldas JP, Braghini CA, Mazzola TN, Vilela MM, Marba ST. Periintraventricular hemorrhage and oxidative and inflammatory stress markers in very-low birth weight newborns. J Pediatr (Rio J) 2015; 91(4): 373-9.

[32] Zhang ZY, Yang MF, Wang T, Li DW, Liu YL, Zhang JH, et al. Cysteamine alleviates early brain injury via reducing oxidative stress and apoptosis in a rat experimental subarachnoid hemorrhage model. Cell Mol Neurobiol 2015; 35(4): 543-53. 